\title{
ESTIMATION OF MONTHLY AVERAGE DAILY DIFFUSE SOLAR RADIATION USING EMPIRICAL MODELS FOR KATHMANDU NEPAL
}

\author{
B. Pandey, R. P. Aryal, C. L. Gnawali, K. N. Poudyal, \\ I. B. Karki and I. Koirala
}

Journal of Nepal Physical Society

Volume 5, Issue 1, October 2019

ISSN : $2392-473 X$

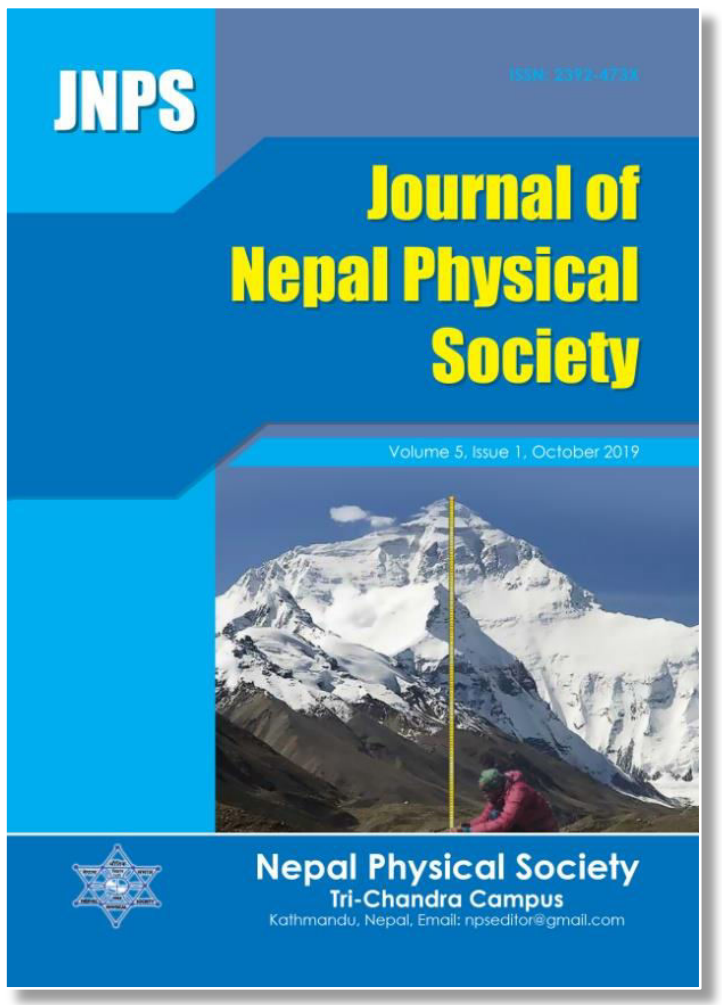

JNPS, 5 (1), 6-13 (2019)

\section{Editors:}

Dr. Vinaya Kumar Jha

Dr. Binod Adhikari

Dr. Kapil Adhikari

Published by:

Nepal Physical Society

P.O. Box: 2934

Tri-Chandra Campus

Kathmandu, Nepal

Email:npseditor@gmail.com 


\title{
ESTIMATION OF MONTHLY AVERAGE DAILY DIFFUSE SOLAR RADIATION USING EMPIRICAL MODELS FOR KATHMANDU NEPAL
}

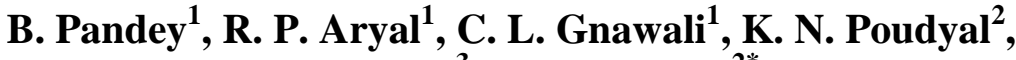 \\ I. B. Karki ${ }^{3}$ and I. Koirala ${ }^{2 *}$ \\ ${ }^{I}$ Pulchowk Campus, IOE, Tribhuvan University, Lalitpur, Nepal \\ ${ }^{2}$ Central Department of Physics, Tribhuvan University, Kirtipur, Nepal \\ ${ }^{3}$ Nepal Open University, Nepal \\ "Corresponding Email: ikphysicstu@gmail.com
}

\begin{abstract}
An accurate knowledge and data of solar radiation and its component are indispensable for the utilization of solar energy. However radiation data are often inaccessible. In this regard, the empirical models are reliable tools. This paper aims to develop and evaluate three simple empirical models (linear, quadratic, and cubic) for estimation of monthly average daily diffuse solar radiation of Kathmandu. Developed Models correlates diffuse fraction with clearness index are based on the satellite data from the NASA Langley Research Center. The performance of models is found to be statistically significant which has been analyzed in terms of statistical indicators like RMSE, MBE and $\mathrm{R}^{2}$. Among the three models, the cubic model is best fit on the basis of statistical parameters. So that cubic model is recommended for the estimation of monthly average daily diffuse radiation at Kathmandu and similar climatic sites of Nepal.
\end{abstract}

Key words: solar radiation, empirical model, diffuse fraction, satellite data, statistical indicators

\section{INTRODUCTION}

Sun is a source of various form of energy for life in earth. It is mainly composed of hydrogen and helium and the fusion of hydrogen to helium is believed to be the sources of energy of the sun [1]. Solar energy is radiated in the form of radiation where $95 \%$ of energy lies in the wavelength range of $0.3-2.4 \mu \mathrm{m}$ which comprises ultraviolet, visible and infrared portion of an electromagnetic spectrum. Solar radiation arriving at the earth surface gets through the constituent of the atmosphere. The earth atmosphere consists of $\mathrm{N}_{2}, \mathrm{O}_{2}, \mathrm{Ar}$ and $\mathrm{CO}_{2}$ as a permanent constituent. In addition the earth atmosphere contains water vapor and particulate matters such as dust, soot, water drops and ice crystals which vary spatially and temporally. Consequently this atmospheric component modifies the solar radiation arriving at the surface by scattering, reflection and absorption [2, 3].

Atomic and molecular oxygen and nitrogen as well as ozone prevent harmful shortwave radiation of wavelength below $0.3 \mu \mathrm{m}$ from reaching the earth surface by absorption. Apart from this, diatomic oxygen has weak absorption bands in the visible spectrum but ozone has a strong absorption band in the visible region from 0.45 to $0.77 \mu \mathrm{m}$.In addition, molecular absorber like $\mathrm{H}_{2} \mathrm{O}, \mathrm{CO}_{2}$, oxides of nitrogen and hydrocarbon combination are active mainly in near and far infrared wavelength region.

The incident beam get attenuated by Rayleigh scattering which occur due to scattering of shortwave radiation by air molecules in the upper layers of atmosphere uniformly in forward and rear direction. However scattering by water vapor, dust particle or aerosols whose size is comparable to the wavelength of incident radiation, the scattered energy is concentrated in forward direction known as Mie scattering and these phenomena are basically responsible for the generation of diffuse radiation. The radiation which evades absorption and scattering and arriving on ground directly in line from the solar disk is called direct or beam radiation $[2,3]$. Consequently the solar radiation arriving at the earth surface also known as global solar radiation comprises of diffuse and direct radiation [4]. The global solar radiation is of immense importance as it can direct our development on low carbon trajectory [5]. 
Nevertheless diffuse components of GSR have a great interest because of its existence throughout the day in adverse as well as fine weather. In most cities of the world, direct radiation is hindered enhancing diffuse radiation by smokes and dust particles in the atmosphere [6].

In order to assess insolation on inclined surface for the operation and design of solar power separate value of direct and diffuse radiation on horizontal surface are required [2, 7]. Apart from this study has shown that radiation use efficiency is high for diffuse radiation by plant canopies which enhance ecosystem carbon assimilation [8].Indeed diffuse radiation has crucial role on energy efficient design on building industries and on town planning $[9,10$, 11].In order to harness the potentiality of diffuse radiation, data of pertaining location are required which can be achieved by continuous and accurate measurement at that specific location [12].

However measurement of diffuse radiation throughout the world is sparse due to economic and technical constraint $[13,14,15]$. In absence of these measurement one have to rely either on existing methods conducive to climatic condition of specific location or develop a new one on the basis of available meteorological data $[16,17,18]$.Several approaches are in practice for the estimation of diffuse solar radiation on horizontal surface. Among them Liu and Jordan pioneered theoretical methods of diffuse fraction as a function of clearness index ,followed by page and Iqbal is extensively used in either linear, polynomial, logarithmic, exponential, power or inverse form [2]. Further diffuse fraction or diffuse coefficients are correlated with clearness index or sunshine hours or both. Jamil et al. (2017) proposed sixteen models correlating diffuse fraction and diffusion coefficient with clearness index based on aforementioned functional form for the estimation of monthly average daily diffuse solar radiation for city of Aligarh. Similar functional form has been proposed correlating diffuse fraction with clearness index for the province of Erzincan turkey as well as by Boukelia et al. at six different sites of Algeria [15, 12]. Okundamiya et al. and Datta et al. proposed second and third order polynomial correlation between diffuse fraction and clearness index for three cities of Nigeria and Dhaka respectively $[17,7]$. They further assess the predictability of developed model over existing empirical models. In addition to it diffuse fraction or coefficient are correlated with other atmospheric variables like temperature, relative humidity, ratio of maximum to minimum temperature etc. $\mathrm{Li}$ et al. for Guangzhou china and Karakoti et al. for India employed this approach to develop new models with enhanced predictability over existing models (based on correlation of diffusion fraction or coefficient with clearness index or sunshine fraction or both) in literature [13,18]. In the location where diffuse radiation data are not available the researchers has used the models available in the literature conducive to their climatic condition to determine the diffuse radiation and hence develop an appropriate model [19, 20, 4, $10]$.

Among 282 meteorological stations at various parts of Nepal, few of them are equipped to carry out the measurement of global solar radiation on horizontal surface [21]. Hence researches usually relies on these data for the study as well as development of more appropriate models which can support the potential applicability of solar radiation on various sector of interest. However study and measurement of diffuse solar radiation has not been carried out yet. This paper aspire to develop an empirical models for the estimation of monthly mean daily diffuse solar radiation for Kathmandu, Nepal using satellite data.

\section{CLIMATIC PROPERTIES}

Kathmandu valley, hub of cultural and historical heritage ,inhabited by $2.5 \mathrm{M}$ people is a capital cities of Nepal lies at $27.42 \mathrm{~N}$ and $85.22 \mathrm{E}$ at mean elevation of about $1337 \mathrm{~m}$ from sea level [22,23]. It is characterized by subtropical cool temperate climate where temperature normal varies from a minimum of $2.4^{\circ} \mathrm{C}$ for January to maximum of 29.1 ${ }^{\circ} \mathrm{C}$ for June with annual average of mean temperature normal of $18.4^{\circ} \mathrm{C}$. The annual average of precipitation normal is $1454.8 \mathrm{~mm}$, most of which falls during monsoon $[24,25]$. Since a measured data of diffuse radiation on horizontal surface are not available so a monthly average data of daily diffuse and global solar radiation on horizontal surface over the period of 22 years (1983-2005) was obtained from surface meteorological and solar energy (SSE) web portal supported by NASA LARC.

\section{METHODOLOGY}

In this study empirical models are developed correlating diffusion fraction $\left(\overline{\mathrm{H}}_{\mathrm{d}} / \overline{\mathrm{H}}_{\mathrm{g}}\right)$ with clearness index $\left(\overline{\mathrm{K}}_{\mathrm{T}}=\overline{\mathrm{H}}_{\mathrm{g}} / \overline{\mathrm{H}}_{\mathrm{o}}\right)$ as follows 
Linear model:

$$
\frac{\overline{\mathrm{H}}_{\mathrm{d}}}{\overline{\mathrm{H}}_{\mathrm{g}}}=\mathrm{a}+\mathrm{b}\left(\overline{\mathrm{K}}_{\mathrm{T}}\right)
$$

Quadratic model:

$$
\frac{\overline{\mathrm{H}}_{\mathrm{d}}}{\overline{\mathrm{H}}_{\mathrm{g}}}=\mathrm{a}+\mathrm{b}\left(\overline{\mathrm{K}}_{\mathrm{T}}\right)+\mathrm{c}\left(\overline{\mathrm{K}}_{\mathrm{T}}\right)^{2}
$$

Cubic model:

$$
\frac{\overline{\mathrm{H}}_{\mathrm{d}}}{\overline{\mathrm{H}}_{\mathrm{g}}}=\mathrm{a}+\mathrm{b}\left(\overline{\mathrm{K}}_{\mathrm{T}}\right)+\mathrm{c}\left(\overline{\mathrm{K}}_{\mathrm{T}}\right)^{2}+\mathrm{d}\left(\overline{\mathrm{K}}_{\mathrm{T}}\right)^{3}
$$

Where $\overline{\mathrm{H}}_{\mathrm{g}}$ is the monthly average of daily global solar radiation on a horizontal surface, $\overline{\mathrm{H}}_{\mathrm{o}}$ is the monthly average of extraterrestrial solar radiation on horizontal surface, $\overline{\mathrm{H}}_{\mathrm{d}}$ is the monthly average daily diffuse solar radiation in horizontal surface. The constant a, b, c, d are location specific empirical coefficient to be determined from regression analysis.

The monthly average daily extraterrestrial solar radiation $\overline{\mathrm{H}}_{\mathrm{o}}$ is estimated using,

$$
\overline{\mathrm{H}}_{\mathrm{o}}=\frac{1}{\mathrm{n}_{2}-\mathrm{n}_{1}} \sum_{\mathrm{n}_{1}}^{\mathrm{n}_{2}} \mathrm{H}_{\mathrm{o}}
$$

Where $\mathrm{n}_{1}$ and $\mathrm{n}_{2}$ are the day number at beginning and end of the month respectively and $\mathrm{H}_{\mathrm{o}}$ is given by

$$
\begin{aligned}
& \mathrm{H}_{\mathrm{o}}=\frac{24}{\pi} \mathrm{I}_{\mathrm{Sc}}\left(1+0.033 \cos \frac{360}{365} \mathrm{n}\right)\left(\omega \frac{\pi}{180} \sin \emptyset \sin \delta+\cos \emptyset \cos \delta \sin \omega\right) \\
& \delta=23.45 \sin \left(\frac{360}{365}(284+\mathrm{n})\right) \\
& \omega=\cos ^{-1}(-\tan \emptyset \tan \delta)
\end{aligned}
$$

Here $I_{s c}$ is the solar constant, $\varphi$ is the latitude of the site, $\delta$ is the solar declination, $\omega$ is the hour angle, $n$ is the Julian days starting from $1^{\text {st }}$ of January [2].

\section{RESULT AND DISCUSSION}

The monthly average data of extraterrestrial, global and diffuse solar radiation on horizontal surface and $\mathrm{K}_{\mathrm{T}}$ for Kathmandu averaged over 22 years period are given in table1. The regression analysis was carried out to determine the regression constant a, b, c, d of our empirical model. The accuracy of predictive model has been evaluated on the basis of some commonly used statistical test for solar radiation models like mean bias error (MBE), root mean square error (RMSE), correlation coefficients $(\mathrm{R})$ and coefficient of determination $\left(R^{2}\right)$ [2]. The empirical constant, $R, R^{2}, M B E$, RMSE are summarized in Table 2.

Table1: Input parameter for Analysis.

\begin{tabular}{|c|c|c|c|c|}
\hline Month & $\begin{array}{c}\overline{\mathbf{H}}_{\mathbf{d}} \\
\left(\mathbf{M J} / \mathbf{m}^{2} / \mathbf{d a y}\right)\end{array}$ & $\begin{array}{c}\overline{\mathbf{H}}_{\mathbf{g}} \\
\left(\mathbf{M J} / \mathbf{m}^{2} / \mathbf{d a y}\right)\end{array}$ & $\begin{array}{c}\overline{\mathbf{H}}_{\mathbf{o}} \\
\left(\mathbf{M J} / \mathbf{m}^{2} / \mathbf{d a y}\right)\end{array}$ & $\overline{\mathbf{K}}_{\mathbf{T}}$ \\
\hline Jan & 2.95 & 15.34 & 22.64 & 0.68 \\
\hline Feb & 3.67 & 18.54 & 26.89 & 0.69 \\
\hline Mar & 4.68 & 22.25 & 32.35 & 0.69 \\
\hline Apr & 6.16 & 24.34 & 37.14 & 0.66 \\
\hline May & 7.67 & 24.05 & 39.91 & 0.60 \\
\hline Jun & 8.86 & 20.70 & 40.83 & 0.51 \\
\hline Jul & 8.93 & 17.24 & 40.25 & 0.43 \\
\hline Aug & 8.24 & 17.28 & 38.01 & 0.45 \\
\hline Sep & 7.09 & 16.42 & 33.88 & 0.48 \\
\hline Oct & 4.50 & 18.47 & 28.43 & 0.65 \\
\hline Nov & 2.66 & 16.99 & 23.53 & 0.72 \\
\hline Dec & 2.45 & 14.94 & 21.26 & 0.70 \\
\hline
\end{tabular}


Table 2: Summary of Regression constants with statistical indicator.

\begin{tabular}{|l|l|l|l|l|l|l|l|}
\hline Model & a & b & $\mathrm{c}$ & $\mathrm{d}$ & $\mathrm{R}^{2}$ & $\begin{array}{l}\mathrm{MBE} \\
\left(\mathrm{MJ} / \mathrm{m}^{2} / \text { day }\right)\end{array}$ & $\begin{array}{l}\mathrm{RMSE} \\
\left(\mathrm{MJ} / \mathrm{m}^{2} / \text { day }\right.\end{array}$ \\
\hline Linear & 1.0371 & -1.2193 & & & 0.9907 & -0.0329 & 0.2249 \\
\hline Quadratic & 0.8384 & -0.5045 & -0.6208 & & 0.9908 & -0.0257 & 0.2001 \\
\hline Cubic & 1.5750 & -4.4449 & 6.2887 & -3.978 & 0.9902 & -0.0243 & 0.1932 \\
\hline
\end{tabular}

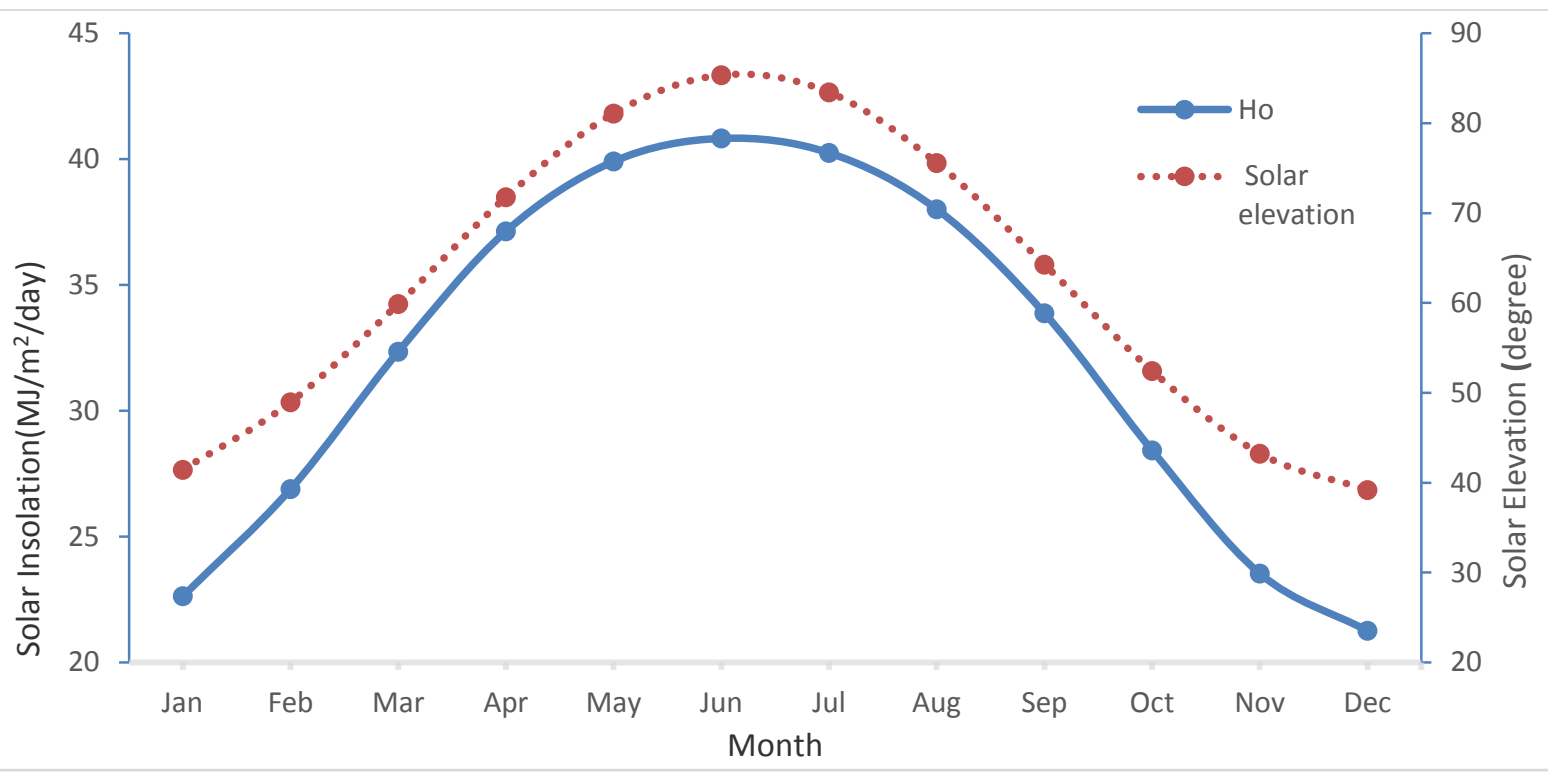

Fig. 1: Variation of monthly average extraterrestrial solar radiation and solar elevation.

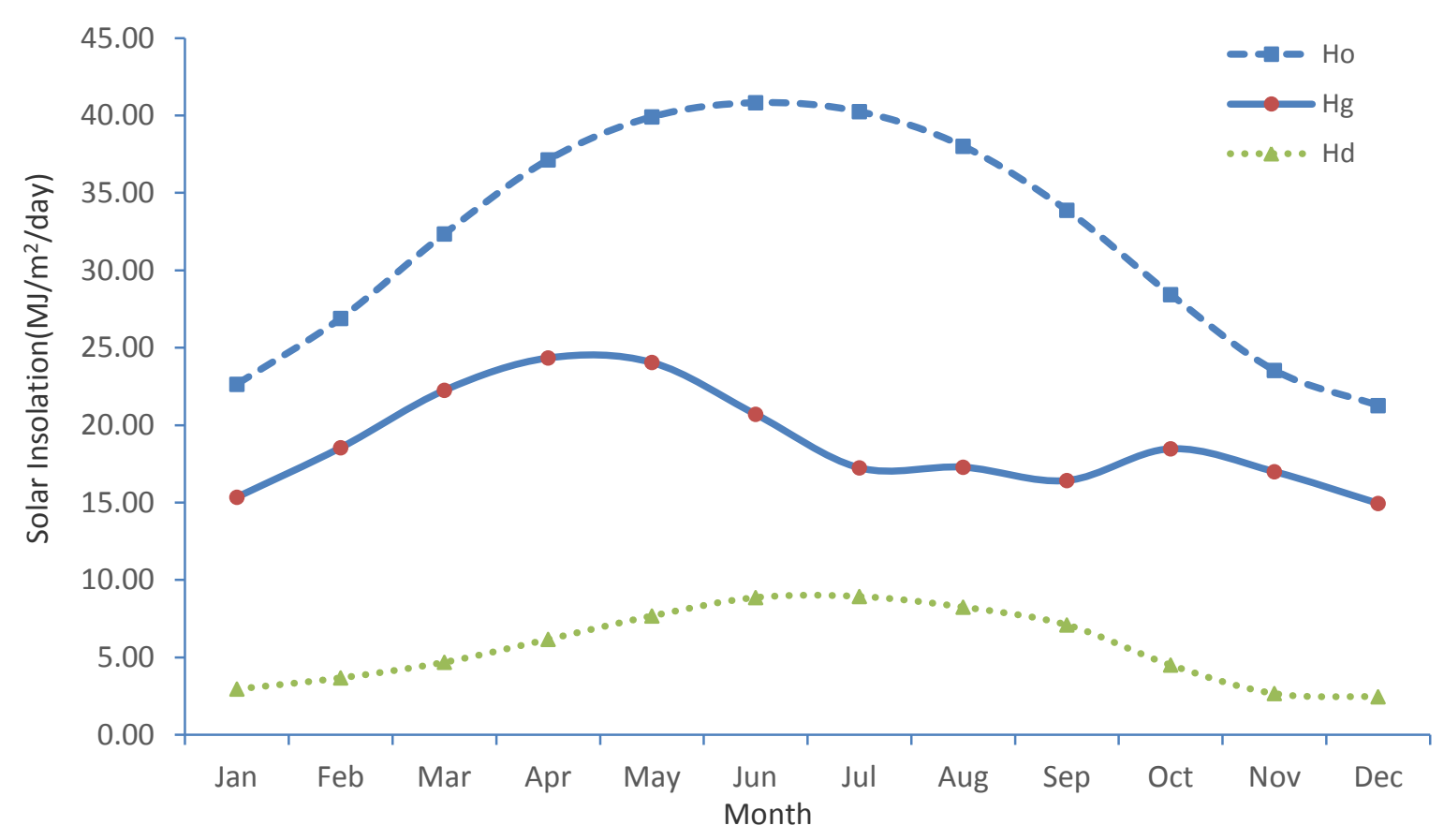

Fig. 2: Comparison of monthly average extraterrestrial solar radiation with monthly average global solar radiation and daily diffuse solar radiation on horizontal surface of Kathmandu. 
Estimation of Monthly Average Daily Diffuse Solar Radiation ...

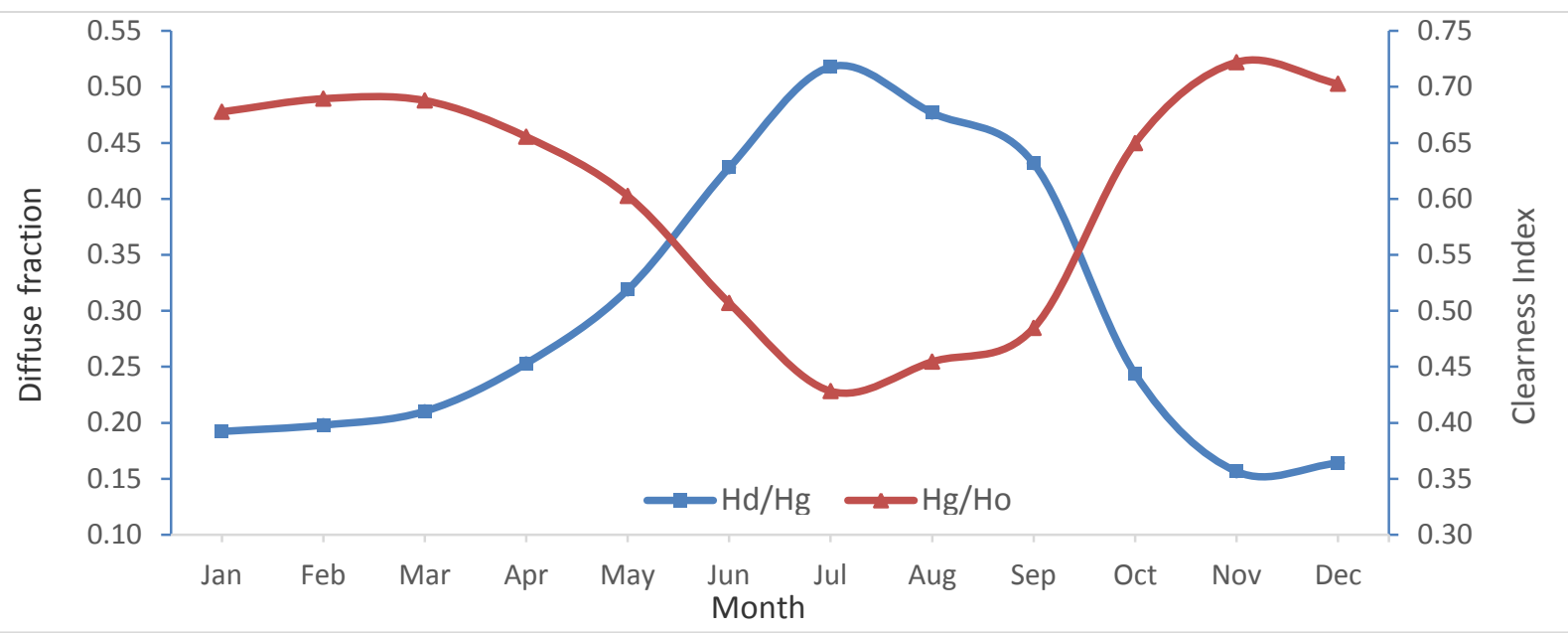

Fig. 3: Comparison of monthly average clearness index with diffuse fraction.

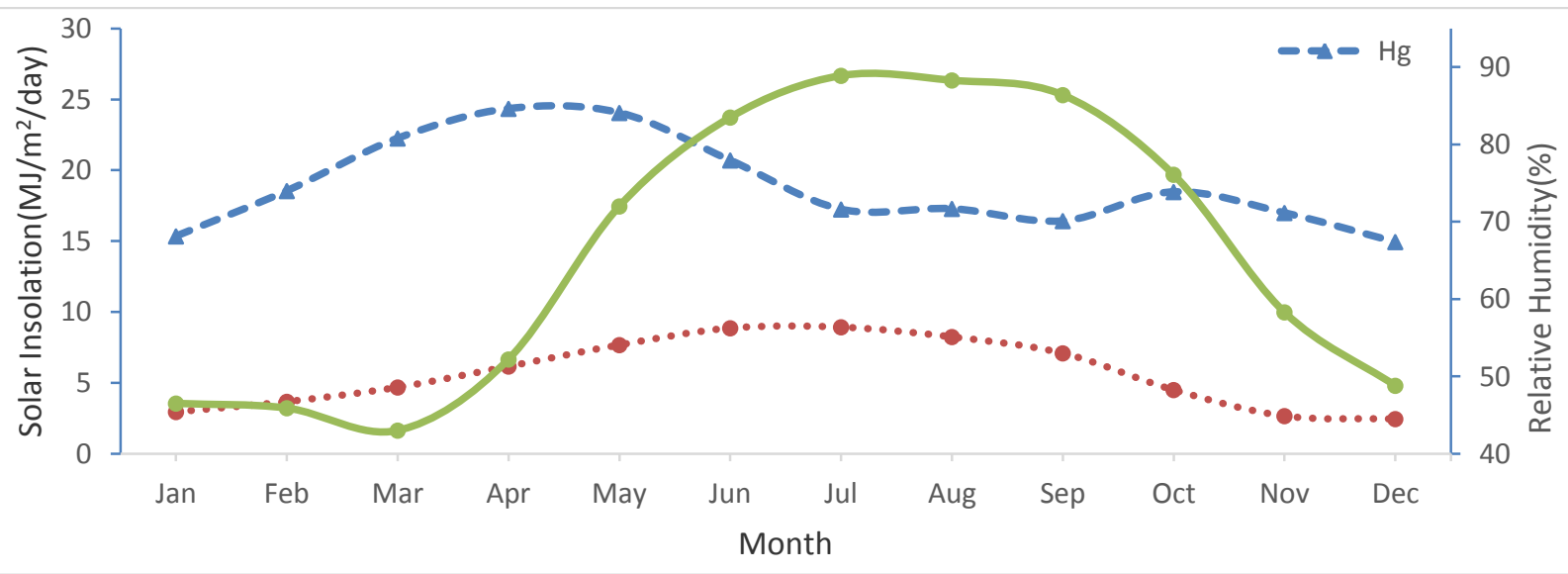

Fig. 4: variation of monthly average daily diffuse solar radiation and global solar radiation on horizontal surface with relative humidity for Kathmandu.

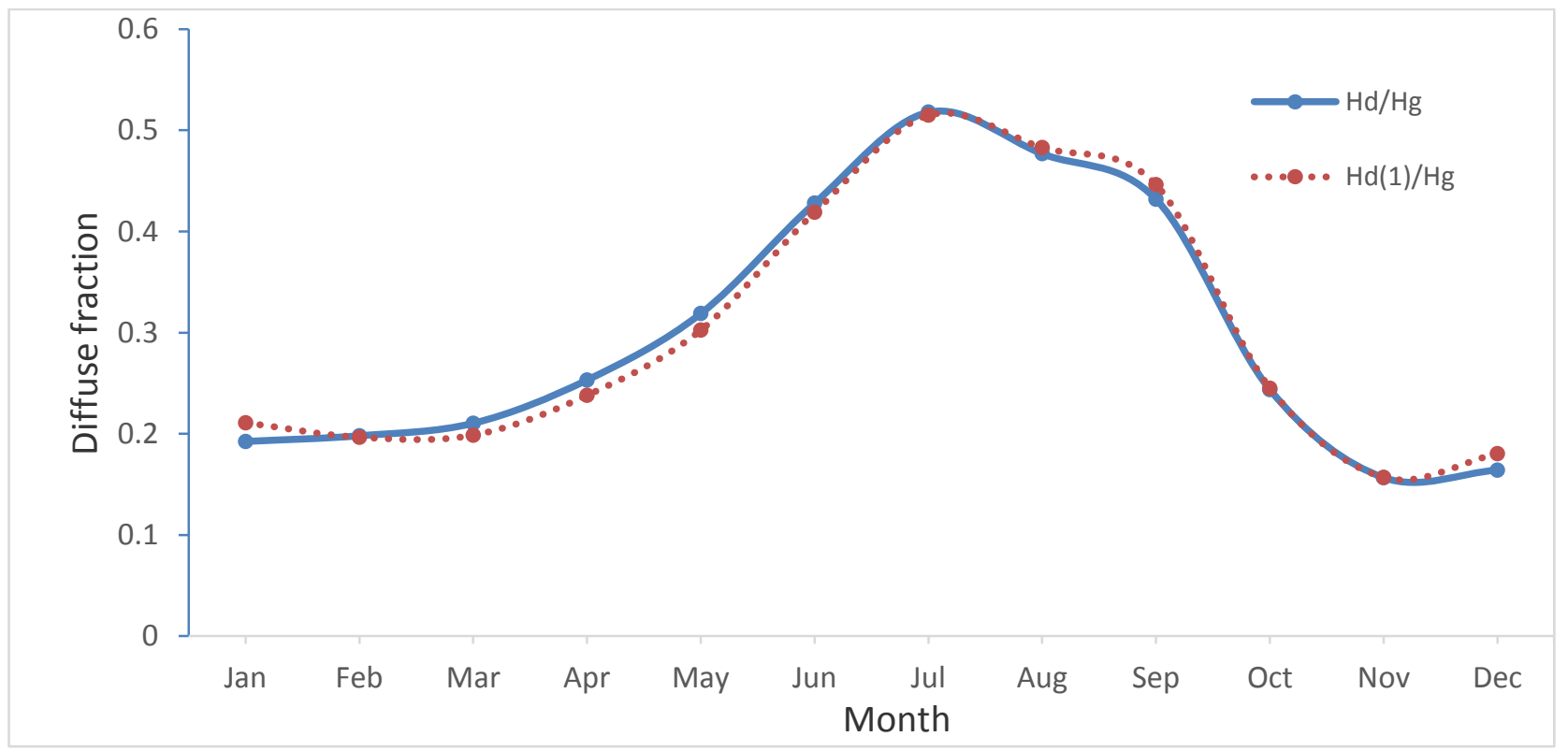

Fig. 5: Monthly variation of diffuse fraction for measured and linear model. 


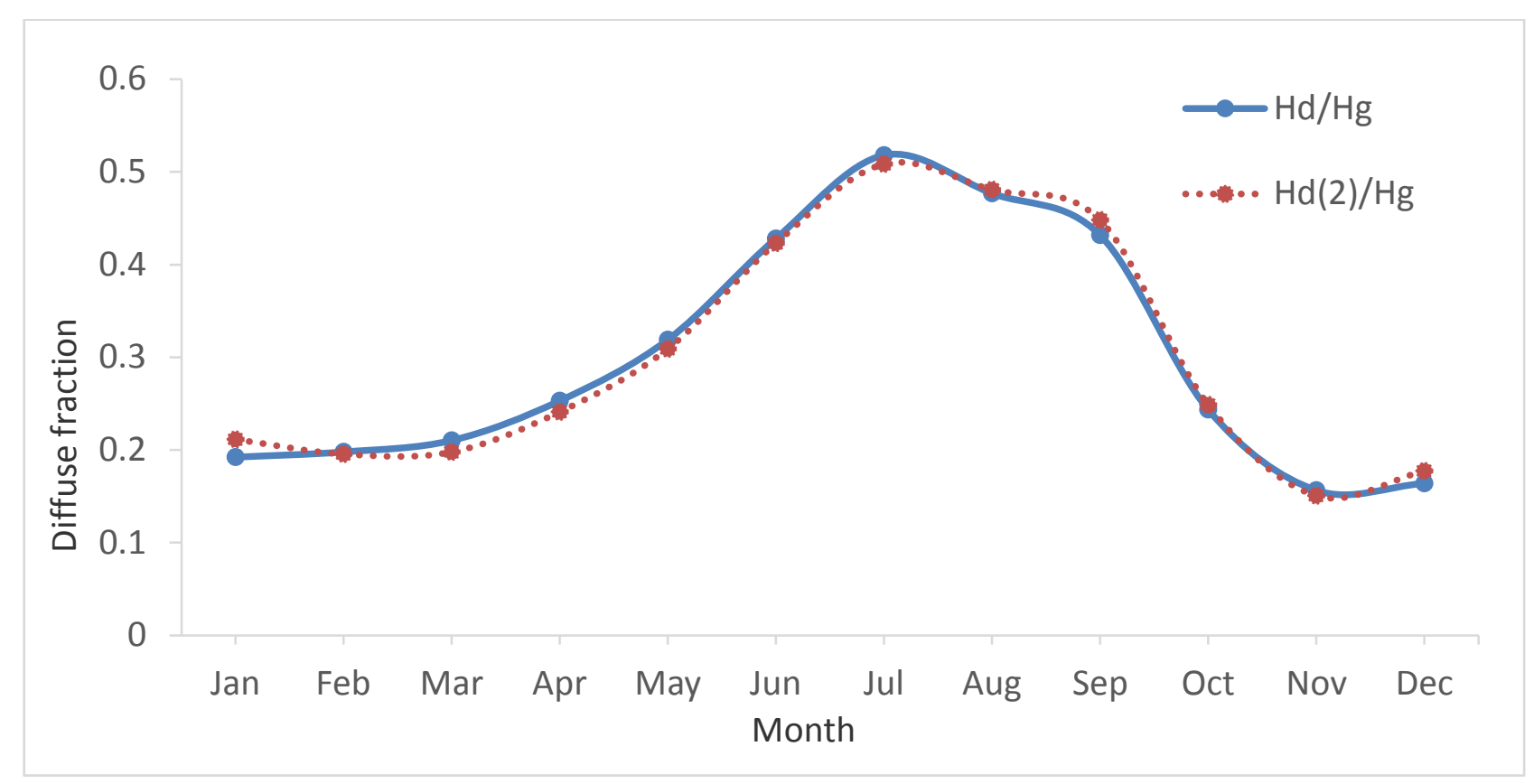

Fig. 6: Monthly variation of diffuse fraction for measured and quadratic model.

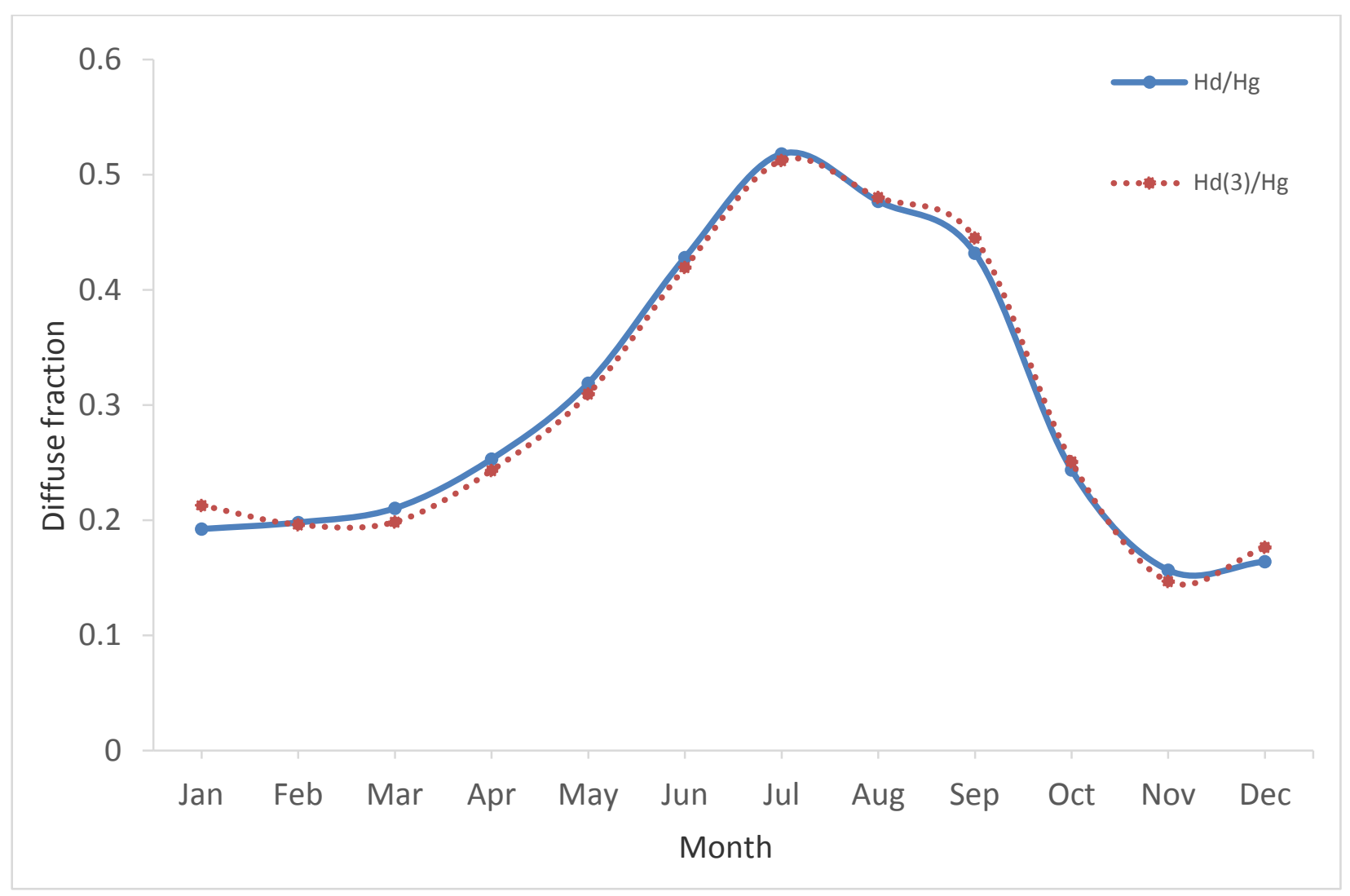

Fig. 7: Monthly variation of diffuse fraction for measured and cubic model.

In Figure 1 the varying monthly average extraterrestrial solar radiation attain the maxima of $40.83 \mathrm{MJ} / \mathrm{m}^{2} /$ day on month of June and minima of $21.26 \mathrm{MJ} / \mathrm{m}^{2} /$ day on the month of December whose variation can be attributed on solar altitude as depicted in a figure. The solar flux depends on the solar altitude since higher is the altitude less slanting is the solar radiation and intense flux will be received [26]. Figure 2 shows that global solar radiation on horizontal surface generally decreases 
from June to September .However the monthly average daily diffuse radiation is peaked on 8.93 $\mathrm{MJ} / \mathrm{m}^{2} /$ day at the month of July. $80 \%$ of total annual precipitation occurs within second week of June to fourth of September, known as monsoon season characterized by cloudy and rainy days. In addition to it, July is the wettest month of the year with the precipitation normal of $363.4 \mathrm{~mm}$ [27, 24].Despite the extraterrestrial radiation is at peak the scattering, absorption as well as reflection of solar radiation by water vapor, dust and the overcast sky are responsible for the suppression of direct or a beam component of global solar radiation and augment the diffuse radiation [28]. Figure 3 show the reverse pattern on monthly variation of diffusion coefficient with respect to clearness index. It has been found that the relative humidity is above the annual average of $65.9 \%$ with in May to October [29]. Figure 4 shows the positive correlation for the variation of monthly average daily diffuse solar radiation with relative humidity for Kathmandu. The clearness index attain highest value of 0.72 in the month of November being a post monsoon driest month with precipitation normal of $8.3 \mathrm{~mm}$ as well as washing away of industrial pollution and aerosols [26, 27, 24]. Study reveal that the diffuse component of global solar radiation is about $46 \%$ during the monsoon period and its annual average is $30 \%$. The atmospheric pollutants of anthropogenic origin such as industrial and vehicular exhaust, dust from poorly maintained roads and ongoing road expansion and even the bowl shape topography of Kathmandu valley retaining the pollutant are responsible for the diffuse radiation despite the clear sky condition in rest of the season [30]. Fig 5, 6, 7 depicts the monthly variation of measured and estimated diffuse fraction using linear, quadratic and cubic model which resemble well with the satellite measured diffuse fraction however the MBE for all the model are negative which indicate the underestimation of monthly average daily diffuse radiation over satellite measured data.

The value of MBE, RMSE and CC are near to its respective ideal value for all three model indicate that all model are statistically significant however MBE and RMSE signifies that cubic model is superior over linear and quadratic model.

\section{CONCLUSION}

In this study, three empirical model based on satellite data of NASA has been developed correlating diffuse fraction with clearness index.
All the three models are statistically significant and give good estimated result of diffuse solar radiation however statistical test support the cubic model. Hence the cubic model is recommended for the estimation of monthly average daily diffuse solar radiation at Kathmandu as well as other location climatically and geographically resembling to Kathmandu valley. These models can be further validated if ground based measurement of diffuse radiation are carried out as a future research.

\section{ACKNOWLEDGEMENT}

The authors would like to thank Department of Hydrology and meteorology for providing climate normal and NASA Langley Research Centre (LRC) power project funded through the NASA Earth science/Applied science program for providing data on monthly average daily diffuse solar radiation, global solar radiation, and monthly average relative humidity for 22 years period.

\section{REFERENCES}

[1] K. N. Liou, An introduction to atmospheric radiation, Academic press (2002).

[2] M. Iqbal, An introduction to solar radiation, New york: Academic press (1983).

[3] J. A. Duffie and W. A. Beckman, Solar Engineering of Thermal Processes, John Wiley \& sons, Ins (2013).

[4] E. O. Falayi, A. B. Rabiu, R. O. Teliat, Correlations to estimate monthly mean of daily diffuse solar radiation in some selected cities in Nigeria, Advances in Applied Science Research, 2(4) pp. 480-490 (2011).

[5] B. Pandey, C. L. Gnawali, R. P. Aryal , K. N. Poudyal,Prediction of global solar radiation using meterological parameters on emperical model at mountain region Jumla,Nepal,Research Journal of Chemical Sciences, 8(1) pp. 23-29 (2018).

[6] Insolation and Artificial Lighting in Relation to Housing and Town-Planning, Journal of the American Institute of planners, 5(2), pp. 50-54 (1939). doi:10.1080/01944363908978826

[7] D. Datta, U. K. Das, S. B. Alam , M. M. Islam, Modeling monthly average daily diffuse radiation for Dhaka, Bangaladesh, International Journal of Research in Engineering and Technology, 2(12) pp.540-544 (2013).

[8] L. Gu, D. Baldocchi, S. B. Verma ,P. R. Dowty, Advantage of diffuse radiation for terrestrial ecosystem productivity, Journal of Geophysical Research Atmosphere, 107(D6),ACL 2-1-ACL 223 (2002). https://doi.org/10.1029/2001JD001242 
[9] H. Wang, F. Sun, T. Wang , L. Wenbin, Estimation of daily and monthly diffuse radiation for from measurement of global solar radiation a case study across China, Renewable Energy, 126,226-241 (2018).

https://doi.org/10.1016/j.renene.2018.03.029

[10] N. N. Gana, J. K. Rai,M. Momoh,Estimation of Global and Diffuse Solar Radiation for Kebbi,Northwestern Nigeria, International Journal of Scientific \& Engineering Research, 5(1),1654-1661 (2014).

[11] S. Munawwar, Modelling hourly and daily diffuse solar radiation using world wide database (Ph.D. dissertation) (2006).

https://core.ac.uk/download/pdf/40077375.pdf.

[12] T. E. Boukelia, M.-. S. Mecibah, I. E. Meriche, General models for estimation of monthly mean daily diffuse solar radiation (case study: Algeria), Energy Conversion and Management, 81, pp. 211-219 (2014). http://dx.doi.org/10.1016/j. enconman.2014.02.035

[13] H. Li, W. Ma, X. Wang ,Y. Lian,Estimating monthly averagr daily diffuse solar radiation with multiple predictors: A case study, Renewable Energy, 36(7) pp. 1944-1948 (2011). http://dx.doi.org/10.1016/j.renene.2011.01.006

[14] B. Jamil ,N. Akhtar, Estimation of diffuse solar radiation in humid-subtropical climate region of India: Comparison of diffuse fraction and diffusion coefficient models, Energy, 131,149-164 (2017). http://dx.doi.org/10.1016/j.energy.2017.05.018

[15] K. Bakirci , Y. Kirtiloglu, Prediction of diffuse solar radiation using satellite data,International Journal of Green Energy, 15(2), 76-79 (2018). https://doi.org/10.1080/15435075.2018.1423976

[16] N. Arslanoglu,Evaluation and establishment of diffuse solar radiation models for Bursa, Turkey, ENERGY SOURCES, PART A: RECOVERY, UTILIZATION, AND ENVIRONMENTAL EFFECTS, 38(18), pp. 2788-2797 (2016). http://dx.doi.org/10.1080/15567036.2016.1214640
[17] M. S. Okundamiya, A. N. Nzeako, Estimation of Diffuse Solar Radiation for Selected cities in Nigeria,ISRN Renewable Energy, vol. 2011, Article ID 439410, 6 pages, (2011). https://doi.org/10.5402/2011/439410.

[18] I. Karakoti, P. K. Das, S. K. Singh, Predecting monthly mean daily diffuse radiation for India,Applied Energy, 91(1), pp. 412-425 (2012).

[19] M. R. Tanweer, F. Ahmad, Z. Uddin, S. U. Rehman,I. Ulfat,Estimation of Diffuse Solar Radiation from Clearness Index for Multan, Southern Punjab, Pakistan,Journal of Basic \& Applied Sciences, 12,pp. 441-444 (2016).

[20] K. Ulgen and A. Hepbasli,Diffuse solar radiation estimation for Turkey's big cities,Energy Conservation and Management, 50(1) pp. 149156 (2009).

[21] Meterological station (2018). www.dhm.gov.np.

[22] Introduction (2018). www.kathmandu.gov.np.

[23] Central Bureau of Statistics,National Population and Housing Census 2011,Government of Nepal, National Planning Commission Secretariat (2012).

[24] Climate (2018). [Online]. www.dhm.gov.np.

[25] P. R. Pant, D. Dongal, Kathmandu Valley Profile, Kathmandu Metropolitan City (2009).

[26] A. B. Bhattacharya, S. K. Kar, R. Bhattacharya, Diffuse solar radiation and associated meterological parameters in India, Annales Geophysicae, 14(10), pp. 1051-1059 (1996).

[27] Nepal Hydrological and Meteorological Research Centre and Consultancy Pvt.Ltd,Study of climate and clilmatic variation over Nepal,Government of Nepal, Ministry of Science,Technology and Environment Department of Hydrology and Meterology (2015).

[28] J. L. Nayava,Climate of Nepal and their Implication,WWF Nepal, pp 164 (2012).

[29] DATA ACCESS (2018). https://power.larc. nasa.gov.

[30] www.cen.org.np (2014). 